\title{
"De tanto poupar em educação, ficaremos ricos em ignorância": contranarrativas juvenis no movimento de ocupação de escolas no Rio Grande do Sul
}

\author{
Araciele Maria Ketzer \\ Mestre; Universidade Federal de Santa Maria, Santa Maria, RS, Brasil \\ araciele.ketzer@gmail.com

\section{Rosane Rosa} \\ Doutora; Universidade Federal de Santa Maria, Santa Maria, RS, Brasil \\ rosanerosar@gmail.com
}

\section{Resumo}

O movimento de ocupação das escolas públicas brasileiras por estudantes secundaristas no período de 2015-2016 constituiu um fenômeno que evidenciou o protagonismo juvenil e pautou a precariedade da educação básica nas discussões da agenda pública e midiática. Além de ocupar as escolas e as ruas, os/as estudantes ocuparam as redes sociais, como o Facebook, para expressarem suas opiniões e demandas. Partindo desse cenário, nosso objetivo central é investigar como os/as estudantes secundaristas do Rio Grande do Sul mobilizaram-se e apropriaram-se das redes sociais para construir uma comunicação de resistência e sua autorrepresentação. Para tanto, utilizaremos uma combinação de abordagens metodológicas, como a pesquisa exploratória, entrevistas semiestruturadas e a observação online-sistemática das páginas, no Facebook, das escolas ocupadas pelos estudantes entrevistados. Como resultado, podemos destacar a existência de uma gestão participativa e colaborativa, a capacidade de mobilização, postura crítica e política em relação à mídia hegemônica, propositiva em relação à educação pública, e o uso de criativas estratégias e linguagens na autocomunicação e autorrepresentação. Esse cenário remete ao caráter educomunicativo das práticas construídas na mobilização estudantil em prol da educação pública. 
Palavras-chave

Educação pública. Movimento estudantil secundarista.

Educomunicação. Redes sociais. Contranarrativas.

\section{Considerações iniciais}

Iniciamos embalados pelo ritmo e pela reflexão de uma música que nos remete à natureza da nossa investigação. Interpretada pela banda Charlie Brown Jr, a música Não é sério traduz em canção uma crítica sobre a representação do/da jovem na mídia brasileira. Nos versos "Eu vejo na TV o que eles falam sobre o jovem não é sério. 0 jovem no Brasil nunca é levado a sério" (ABRAO, DUARTE, CARVALHO, PERES, 2000), está explícita uma realidade que observamos frequentemente na cobertura jornalística dos meios hegemônicos, bem como em outros produtos midiáticos cujos discursos conectam a identidade juvenil a significações negativas.

No contexto das mobilizações sociais que ocorrem no âmbito da educação pública, como a greve dos professores, os discursos que circulam na mídia, em geral, representam o/a estudante nas notícias como vítima da paralisação, um "sujeito de necessidade" (MATA, 2006). Tal conjuntura foi revestida de novas perspectivas a partir do fenômeno das ocupações nas escolas públicas do Brasil pelos estudantes secundaristas no período de 2015 e 2016.

A resistência iniciou em novembro de 2015, em São Pauloํㅜ, com a ocupação de mais de 200 escolas estaduais. Em dezembro, o movimento ganhou força no estado de Goiás, e, no início de 2016, estudantes de outras regiões do país, como Rio de Janeiro, Ceará, Mato Grosso e Rio Grande do Sul, aderiram à mobilização, que se estendeu até julho desse ano, em uma primeira onda de ocupações.

No Rio Grande do Sul, as ocupações iniciaram em meados do mês de maio de 2016, sendo o Colégio Estadual Coronel Emilio Afonso Massot, localizado em Porto Alegre, o primeiro do estado a ser ocupado. No total, foram mais de 150 escolas gaúchas participantes da mobilização. Entre as reinvindicações unânimes dos/das estudantes rio-grandenses estavam os cancelamentos do Projeto de Lei (PL) 44 - que prevê que organizações sociais

\footnotetext{
1 Os estudantes lutaram contra o projeto do governador Geraldo Alckmin de Reorganização Escolar. O projeto consistia em concentrar alunos e alunas de determinadas faixas etárias em escolas de ciclo único, ou seja, cada unidade de ensino teria

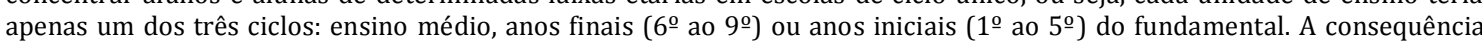
seria o fechamento de mais de 90 escolas da rede pública estadual. A partir da luta estudantil, o governo adiou a execução do projeto.
} 
"De tanto poupar em educação, ficaremos ricos em ignorância": contranarrativas juvenis no movimento de ocupação de escolas no

gerenciem áreas como a educação (RIO GRANDE DO SUL, 2016) - e do PL 190 - projeto da chamada "Escola sem Partido" que propõe, por sua vez, a implantação de um ensino mais "neutro" em relação a posicionamentos políticos e ideológicos dos professores e professoras nas instituições de ensino básico (RIO GRANDE DO SUL, 2015).

A voz de resistência dos estudantes, além dos múltiplos aprendizados, conquistou o adiamento da votação de tais projetos de lei e a liberação de recursos financeiros para a infraestrutura das escolas. Além disso, resultou na criação de um Fórum de Educação para cada região do estado - com a proposta de que, mensalmente, representantes estudantis, representantes do Ministério Público e representantes do governo reúnam-se para discutir as pautas da educação. Nesse sentido, é válido destacar aqui a voz propositiva que os/as estudantes conquistaram ao ter um espaço no qual discutem, de forma protagonista e sistemática, demandas da sua escola e do ensino público.

Em outubro de 2016, teve início, no estado do Paraná, uma segunda onda de resistência e mobilização que envolveu a ocupação de mais de 1000 mil escolas em todo país. Esse movimento seguiu as estratégias da mobilização anterior, agora lutando contra a Medida Provisória (MP) 746 - que propõe a reforma no Ensino Médio, anunciada pelo governo de Michel Temer - e contra a Proposta de Emenda Constitucional (PEC) 241 (ou PEC 55), que previa o congelamento, por 20 anos, dos investimentos em educação, saúde e segurança pública no país.

Apesar de cada contexto de ocupação escolar pelos secundaristas ter suas reivindicações específicas, a pauta principal que se sobressaía a todas elas era a luta pela qualidade da educação básica e pública. Além de ocuparem as escolas públicas e as ruas do país, os/as secundaristas também apropriaram-se significativamente dos espaços comunicativos das redes sociais, tal como o WhatsApp, Instagram, YouTube, Telegram, Snapchat, e principalmente, o Facebook - através das chamadas Fanpages - tanto para a comunicação interna, entre os estudantes, quanto para a externa, com a comunidade, a mídia e o Estado. Através desse processo comunicativo contruiram contranarrativas ${ }^{2}$ em torno da temática da precarização da educação pública e da rotina das ocupações.

Esse cenário nos leva a compreender a mobilização estudantil enquanto um movimento social em rede. Castells (2013) entende esse como um movimento conectado em

\footnotetext{
2 Compreendemos tal conceito como sendo construções discursivas constituídas a partir da apropriação de linguagens plurais e multimídias em contextos midiáticos alternativos aos hegemônicos espaços multimodais, tais como as redes sociais online (narrativas de sites, Facebook, Instagram...) e offline (narrativas de entrevistas, cartazes, discursos...), marcadas pela autorrepresentação dos sujeitos, ou seja, produzidas por quem vive ou está mais próximo da história, contando-a a partir desse lugar de interlocução e resistência.
} 
"De tanto poupar em educação, ficaremos ricos em ignorância": contranarrativas juvenis no movimento de ocupação de escolas no

redes de múltiplas formas, marcado por processos horizontais de comunicação. Sua origem está associada às centelhas de indignação com problemáticas sociais e coletivas. Em geral, essa ação é iniciada na internet, mas acaba tornando-se um movimento ao ocupar o espaço urbano. Por isso, constitui-se também como uma mobilização viral, ao mesmo tempo local e global, além de ter um caráter significativamente político. Nossa proposta de estudo prospera nesse cenário. Dessa forma, investigaremos como os/as estudantes secundaristas do Rio Grande do Sul ${ }^{3}$ mobilizaram-se e apropriaram-se das redes sociais para construirem uma autocomunicação de resistência.

Outra perspectiva é compreender tais processos comunicativos e participativos a partir do prisma da educomunicação. Partindo de uma concepção de educação voltada ao desenvolvimento da cidadania e da emancipação dos sujeitos, tal como defendia Freire (1981), Peruzzo (2000) destaca que as pessoas inseridas em práxis sociais cotidianas envolvem-se num processo de educação informal, o qual está associado às formas de comunicação criadas nessas conjunturas de luta popular, calcadas em um processo horizontal de interlocução - do qual o cidadão/a cidadã se tornam protagonistas.

Nesse sentido, segundo Peruzzo (2000), os sujeitos tendem a agregar elementos a sua cultura e alterar seu modo de ver o mundo, de posicionar-se e intervir crítica e politicamente. Dessa forma, a autora acredita que esses ambientes são propícios para o desenvolvimento da interseção entre comunicação e educação:

As dimensões do engajamento na dinâmica local, conteúdo das mensagens e da participação em todas as fases do processo comunicativo, em geral, acontecem interligadas e se configuram como o ideal em termos de ação edu-comunicativa no âmbito dos movimentos comunitários. (PERUZZO, 2000, p. 220).

Essa relação, no âmbito dos movimentos sociais, também é abordada por Kaplún (2002) através do conceito de comunicação educativa que contempla um resultado formativo. Para tanto, ela deve ser participante, problematizadora, interativa e horizontal. Para o autor, as mensagens e os meios construídos nesses espaços sociais são instrumentos da educação e transformação popular, "Dizemos que produzimos nossas mensagens 'para que os destinatários tomem consciência de sua realidade', ou 'para suscitar uma reflexão', ou para gerar uma discussão." (KAPLÚN, 2002, p. 15, tradução nossa).

\footnotetext{
3 A escolha do recorte de pesquisa no estado é justificada devido à proximidade da pesquisadora a esse campo e também devido à adesão significativa dos/das estudantes nesse contexto. Além disso, essa amostra integra um universo maior de investigação na pesquisa de mestrado no Programa de Pós-graduação em Comunicação da Universidade Federal de Santa Maria, no Rio Grande do Sul, Brasil, na qual investigamos também o movimento de ocupação das escolas nos estados de São Paulo e Paraná.
} 
"De tanto poupar em educação, ficaremos ricos em ignorância": contranarrativas juvenis no movimento de ocupação de escolas no

Partindo dessas perspectivas, integramos o estudo ao campo da interface comunicação/educação - ou educomunicação. Para Soares (2012), a educomunicação é um paradigma, uma orientação para ação, que nasce na América Latina a partir da luta pelos direitos à expressão e à comunicação: “[...] ao longo dos 40 anos houve muito esforço da comunicação popular, da comunicação alternativa. Agora, isso nos permitiu aprender a utilizar os meios a partir de nossas necessidades." (SOARES, 2012, tradução nossa).

Segundo o autor, a educomunicação emerge fortemente no contexto da educação não formal, como em Organizações Não Governamentais (ONGs), movimentos sociais e, mais recentemente, aproximando-se do sistema formal de ensino através de políticas públicas, como um conjunto de ações que empoderam crianças, jovens e adultos à prática da cidadania. Dessa forma, a educomunicação é compreendida como um campo, inter/transdisciplinar e interdiscursivo, caracterizado por áreas de intervenção social, como a gestão da comunicação, a educação para a comunicação, a expressão comunicativa através das artes, a pedagogia da comunicação, a mediação tecnológica nos espaços educativos, a reflexão epistemológica e pela construção de ecossistemas comunicativos.

Conectada com tais pressupostos, na próxima seção, vamos delinear a abordagem metodológica a partir da qual desenvolvemos o estudo.

\section{0 percurso metodológico}

Maldonado (2015) pondera sobre ainda haver uma lógica sistêmica conservadora de "colonialismo intelectual", que regula pesquisas científicas em geral. Para descolonizar, ele propõe avançar em propostas transmetodológicas, visto que "[...] a investigação científica em comunicação precisa da confluência profunda, cooperativa e produtora da estruturação de métodos mistos, múltiplos." (MALDONADO, 2015, p. 720). Seguindo essa abordagem, construímos uma combinação de métodos de base qualitativa, dos quais destacamos a pesquisa exploratória, a partir de visitas realizadas a escolas ocupadas em Santa Maria, Rio Grande do Sul (RS), entrevistas informais (com estudantes, professores e professoras) ${ }^{4}$,

\footnotetext{
${ }^{4}$ A pesquisa exploratória foi realizada no mês de junho de 2016 a partir de visitas e entr evistas com estudantes e professores de seis, das oito escolas que foram ocupadas em Santa Maria. São elas: Escola Estadual de Ensino Médio Cilon Rosa; Escola Estadual de Educação Básica Augusto Ruschi; Escola Estadual de Ensino Médio Professora Maria Rocha; Escola Estadual de Educação Básica Manoel Ribas; Escola Estadual de Educação Básica Profa Margarida Lopes; Instituto Estadual de Educação Olavo Bilac; Colégio Estadual Tancredo Neves.
} 
entrevistas semiestruturadas com estudantes e a observação online-sistemática das páginas no Facebook das escolas ocupadas.

As entrevistas 5 foram realizadas em junho de 2016 com dois estudantes de 16 anos que ocuparam a Escola Estadual de Ensino Médio Cilon Rosa, localizada no centro da cidade de Santa Maria, e a Escola Estadual de Educação Básica Augusto Ruschi, localizada na periferia. A observação online (JOHNSON, 2010) e sistemática (GIL, 2008) foi realizada nas Fanpages Ocupa Augusto Ruschi e Ocupa Cilon Rosa, que correspondem às páginas das escolas ocupadas pelos estudantes entrevistados. Analisamos tais páginas estabelecendo como período de análise os meses ápices da ocupação, ou seja, maio e junho de 2016. No total, foram cerca de 100 postagens coletadas, que incluem imagens, vídeos e notas textuais, conteúdos analisados a partir de três categoriais centrais:

a) contranarrativas sobre a ocupação na escola;

b) contranarrativas sobre a mídia;

c) contranarrativas sobre a educação pública.

Dessa forma, a partir do cruzamento entre os dados obtidos através dessa combinação de diferentes perspectivas metodológicas, buscamos, a seguir, compreender os processos comunicativos constituídos no movimento de ocupação de escolas públicas do Rio Grande do Sul.

\section{As contranarrativas nas escolas e nas redes sociais}

No percurso investigativo das contranarrativas dos/das estudantes secundaristas do Rio Grande do Sul, identificamos a importância das informações compartilhadas na internet e pela própria cobertura da mídia tradicional, para a constituição de uma rede, na qual estudantes gaúchos (e dos demais estados) inspiram-se na mobilização de estudantes em São Paulo, os quais, por sua vez, foram inspirados pela mobilização de estudantes do Chile e Argentina. Configura-se, assim, um movimento ao mesmo tempo local e global. Dessa forma, a mobilização social em rede ocorreu fundamentada em uma tecnologia social

\footnotetext{
5 Na descrição analítica os entrevistados são identificados por meio do nome das escolas, a fim de preservar suas identidades. As falas são designadas por "Entrevista" e a identidicação utilizada para a pessoa entrevistada, como Rosa e Rosa II para depoimentos de estudantes da Escola Estadual de Ensino Médio Cilon Rosa.
} 
"De tanto poupar em educação, ficaremos ricos em ignorância": contranarrativas juvenis no movimento de ocupação de escolas no

transnacional, ou seja, a partir da sistematização e socialização da experiência dos estudantes chilenos e argentinos 6 .

Essa referência contribuiu na formação política dos estudantes - a partir da organização, mobilização, gestão colaborativa e até mesmo pelas estratégias sociais e comunicacionais adotadas ao longo do processo. Isso, segundo Castells, constitui uma característica dos movimentos sociais em rede, "[...] para que as experiências individuais se encadeiem e formem um movimento é a existência de um processo de comunicação que propague os eventos e as emoções a eles associadas." (CASTELLS, 2013, p. 19).

No que se refere às reivindicações, os estudantes que entrevistamos destacam pautas que constituem tanto questões pontuais da escola quanto as que fazem parte da luta estudantil estadual, como o Projeto de Lei (PL) 44 e a PL190. Para uma professora da escola Cilon Rosa, as ocupações podem ser compreendidas como o ressurgimento do movimento estudantil secundarista, "[...] resgatando os estudantes para a cena política, os quais até então estavam anestesiados frente às problemáticas do país." (Entrevista Rosa II). Por sua vez, uma professora da escola Tancredo Neves acredita que essa reação está ligada ao ápice do esgotamento em relação ao descaso com a escola e com a educação básica, que está atingindo diretamente os/as estudantes "em sua própria casa", "em sua própria mesa", conjuntura que, associada à mobilização em rede, desembocou no ato de ocupação. Para ela, o movimento estudantil deu força à mobilização dos professores e professoras, ainda que se tratem de duas atuações autônomas. Acredita ainda que "Apesar de todas as dificuldades, essa atuação dos estudantes mostra que a escola pública está fazendo seu papel de conscientização e de formação cidadã." (Entrevista Neves).

A forma de organização foi delineada através de comissões responsáveis pela alimentação, limpeza, comunicação, cultura e segurança, sendo que havia um rodízio dos/das estudantes que compunham cada uma dessas funções. Outra característica que identificamos nas contranarrativas dos estudantes é a concepção de um movimento autônomo, sem partido e não representado por entidades estudantis como União Brasileira dos Estudantes Secundaristas (UBES).

Entre as redes sociais mais usadas no contexto da ocupação estão o Instagram, o Snapchat, o WhatsApp e, principalmente, as páginas no Facebook. Esses espaços são usados

\footnotetext{
${ }^{6}$ Uma das grandes influências do movimento secundarista no Brasil foi o movimento estudantil do Chile de 2006, também conhecido como a "Revolta dos Pinguins", cujas estratégias foram sistematizadas no manual "Como ocupar um colégio", o qual foi traduzido para o português e apropriado pelo movimento de ocupação dos/estudantes brasileiros. 0 documentário Acabou a paz, isto aqui vai virar o Chile (2016), do diretor Carlos Pronzato, que conta a história das ocupações de escolas públicas de São Paulo, evidencia a influência do movimento estudantil chileno no contexto de mobilização brasileiro. As manifestações estudantis argentinas também são citadas como inspiração do movimento.
} 
para comunicação interna e externa, no sentido de divulgar notas de esclarecimento, publicar a cobertura das atividades que estavam sendo realizadas - tais como oficinas e eventos (cobertura muitas vezes "ao vivo") -, divulgar pedido de doações, além de constituírem um canal de diálogo com a comunidade por meio das ferramentas de troca de mensagens (inbox). Nessas contranarrativas, predomina a estratégia de documentar a rotina no período da ocupação, utilizando o espaço das páginas no Facebook como uma espécie de diário de bordo - prática que é fundamental para a autodefesa do movimento contra críticas externas, seja do governo, da mídia ou da comunidade em geral.

Interessante sublinhar também, como destacou uma professora do Colégio Estadual Manoel Ribas, que a produção de conteúdo para as páginas no Facebook contribuiu para institucionalizar o movimento estudantil secundarista, transmitir credibilidade para a comunidade e tranquilizar também os pais e mães que estavam acompanhando a mobilização de seus filhos: "Quando eles começaram a fazer e divulgar as oficinas, a visibilidade dos estudantes foi melhor." (Entrevista Ribas). Outrossim, em vista da política de aversão à mídia hegemônica, como veremos a seguir, as Fanpages eram usadas pelos veículos de comunicação como fonte de informações oficiais sobre o fato, além de constituírem uma plataforma para registro histórico da ocupação das escolas pelos estudantes.

Quanto à criação desses espaços midiáticos alternativos, a sistemática identificada é: além de cada escola ocupada ter sua própria página no Facebook para divulgar o que estava acontecendo em uma perspectiva local, apoiadores do movimento (universitários, representantes de entidades e movimentos sociais voltados à educação) criavam páginas centrais de cada região para compartilhar e reunir, em um único espaço, os conteúdos produzidos pelas escolas ocupadas, transformando-se em uma espécie de central de informações sobre o movimento estudantil secundarista de cada região. Observamos nessas páginas um número significativo de interações e seguidores. No contexto do Rio Grande do Sul, identificamos com essa perspectiva, a Ocupa Tudo Brasil, a Escolas Gaúchas em Luta, e a Escolas de Luta RS.

Interessante observar que a maior parte dessas páginas (tanto as centrais quanto as locais), criadas para comunicar as ações do movimento, continuam ativas como espaços de discussão e compartilhamento de conteúdo sobre movimentos sociais, educação, escola, política, juventude, cidadania, discriminação, cultura, minorias sociais, entre outros assuntos que traduzem representações e sentidos do ponto de vista da juventude. Esse 
fenômeno é apontado por Castells (2013) quando destaca que a ocupação tanto dos espaços físicos quanto virtuais é importante, pois a internet possibilita que, mesmo com o fim de uma ocupação/mobilização física, as discussões não terminem, mas perdurem, tornando-se pauta pública.

Outro ponto destaque das contranarrativas foram as relações estabelecidas entre os/as secundaristas, a mídia hegemônica e também os meios alternativos. Constatamos que tais tensionamentos foram desenvolvidos de modo distinto: no que se refere à mídia comercial, observamos que, no início do movimento, houve uma tentativa de abertura e negociação, como no caso da realização de uma coletiva de imprensa na escola Cilon Rosa. Contudo, de acordo com os relatos, ao identificarem incoerências nas representações e informações divulgadas sobre o movimento, a reação dos/das estudantes foi assumir uma postura crítica e uma política de preservação e fechamento - o contrário do que ocorria com a mídia alternativa, que, com confiança e parceria, tinha livre acesso às ocupações.

Um movimento interessante foram as contranarrativas (Figura 1) chamadas de notas de repúdio, publicadas nas páginas do Facebook das referidas escolas principalmente na Ocupa Augusto Ruschi - sobre as matérias veiculadas pelas mídias hegemônicas, evidenciando uma prática de leitura crítica da mídia, exercício medular na educomunicação. Nelas, a notícia era dissecada e analisada em vários pontos, perspectiva que também ficava evidente nos relatos. Elementos como título, diagramação, enquadramentos, fontes, fotografias e legendas eram questionados pelos/pelas estudantes quanto a sua intenção, significação e legitimidade. Nessa conjuntura, uma prática perspicaz, que denota essa postura estratégica e crítica dos estudantes, é o monitoramento das notícias sobre o movimento veiculadas nas emissoras de televisão, nos jornais impressos e nos portais de notícias, como Zero Hora e G1. Sobre isso, o estudante da Escola Estadual de Ensino Médio Professor Maria Rocha afirma: "Essas mídias maiores são mídias fortes, mesmo que elas distorçam, a gente precisa saber como elas estão distorcendo pra gente saber como lutar contra isso, então a gente tenta ao máximo ver todos os lados." (Entrevista Rocha). 
"De tanto poupar em educação, ficaremos ricos em ignorância": contranarrativas juvenis no movimento de ocupação de escolas no

Figura 1 - Print Screen de publicação da nota de repúdio à notícia veiculada no jornal Diário de Santa Maria

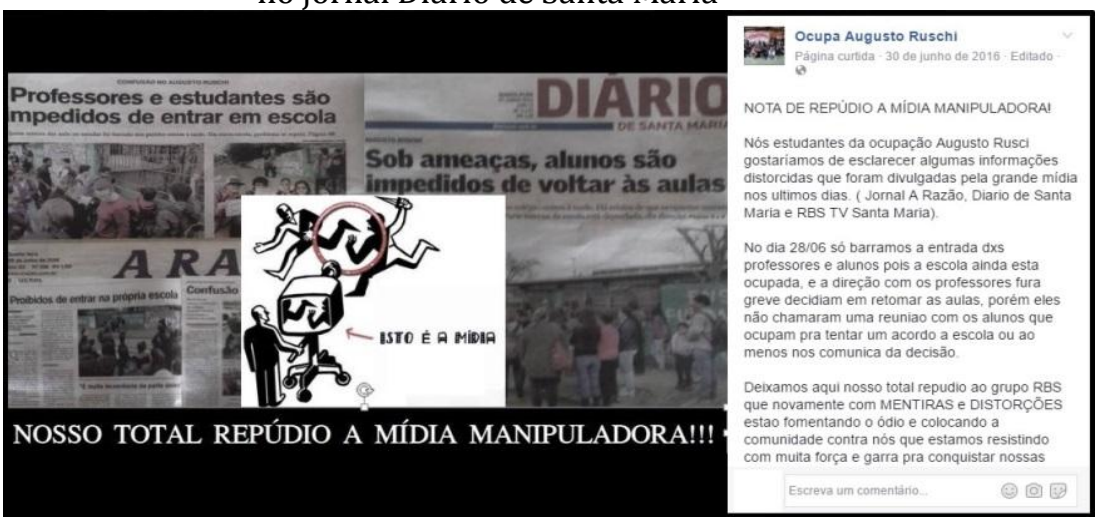

Fonte: Ocupa Augusto Ruschi (2016).

Outrossim, fatos observados no contexto da pesquisa exploratória corroboram esse cenário. Em uma das primeiras visitas que realizamos à ocupação da escola Cilon Rosa, além de solicitar nosso contato e documento (procedimento padrão para todos os visitantes), o estudante responsável pela recepção da ocupação nos perguntou "Você é de alguma mídia paga?". Ao explicar que não, nossa entrada foi autorizada. Além disso, em várias escolas que visitamos, percebemos que os/as estudantes tinham a prática de gravar a conversa que estavam tendo conosco, como uma medida de cautela frente ao que já tinham constatado nas entrevistas concedidas e veiculadas pela mídia comercial.

No Instituto Estadual de Educação Olavo Bilac, também presenciamos repórteres da emissora RBS TV local tentando entrar na escola; contudo, seu acesso foi negado pelos e pelas estudantes, devido à postura de rompimento do diálogo com a mídia hegemônica do movimento como um todo. Essa reação é justificada por uma estudante do Instituto: "Porque a gente tem esse receio de que entrem aqui. Aí tem essas coisas aqui em cima da mesa que está uma bagunça e está acontecendo uma coisa muito legal ali. Mas aí eles vão mostrar apenas a bagunça. Isso mancha muito o movimento." (Entrevista Bilac).

Nesse contexto, o posicionamento dos professores segue a mesma lógica: eles destacam, nos relatos, que a mídia abordou o movimento como uma decorrência do movimento docente, ignorando a capacidade e a legitimidade dos/das estudantes de mobilização autônoma.

É a partir dessa conjuntura crítica que os estudantes optaram por criar sua própria comunicação, apropriando-se dos dispositivos midiáticos e tecnológicos, principalmente das redes sociais, e construindo sua autorrepresentação. Tais espaços são apontados como alternativas à versão da mídia hegemônica, embora estudantes e professores concordem 
"De tanto poupar em educação, ficaremos ricos em ignorância": contranarrativas juvenis no movimento de ocupação de escolas no

sobre seu alcance limitado, bem como sobre a existência das lógicas de interesses comerciais também nesse âmbito da internet. Logo, se os secundaristas são representados como sujeitos de necessidade na mídia hegemônica (MATA, 2006), nas suas contranarrativas, nas redes e nas escolas, por outro lado, eles delinearam uma autorrepresentação predominante como sujeitos de demanda e de decisão, enfatizando a importância e o papel da juventude como sujeitos e atores sociais (TOURAINE, 1997) que desejam participar da luta por uma educação pública de qualidade.

Além dos tensionamentos com a mídia, destaca-se, nas contranarrativas analisadas, significações em torno da educação pública, configuradas por um posicionamento propositivo em relação à escola, ao sistema de ensino, aos professores, e por um posicionamento crítico quando fazem referência ao Estado. Por um lado, os/as estudantes questionam e colocam em evidência a precarização da educação básica e pública; por outro, seja nas entrevistas ou nas postagens das redes online, denotam a sua consciência sobre a importância da educação no desenvolvimento humano, social e econômico. Importante salientar a recorrência da autorrepresentação do secundarista como sujeito também responsável pela educação, que deseja contribuir com a construção da escola, como fica explícito na Figura 2.

Figura 2 - Print Screen de publicação contendo uma imagem que ilustra o jovem protegendo a escola

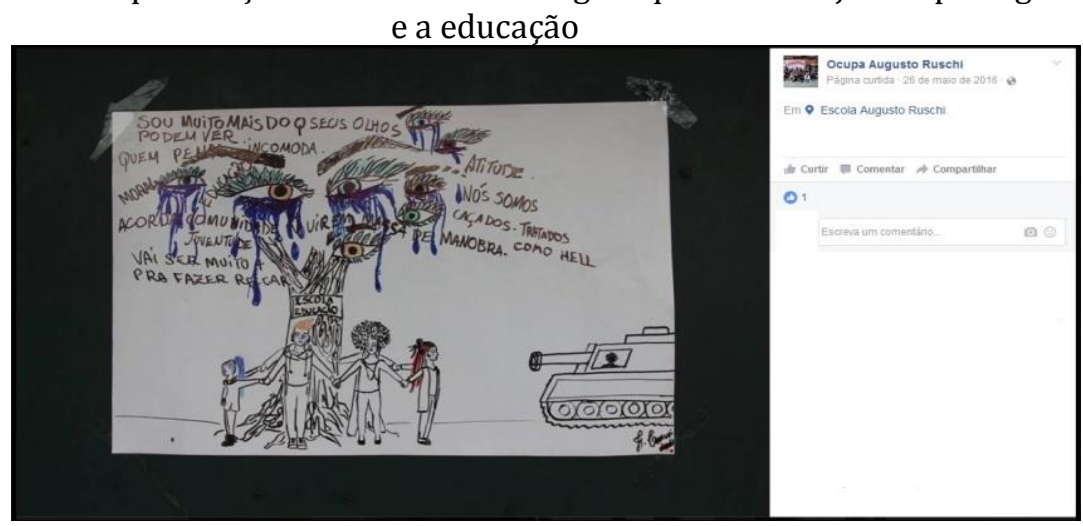

Fonte: Ocupa Augusto Ruschi (2016).

Logo, as ocupações constituíram um meio para chamar a atenção à importância da participação do/da estudante no desenvolvimento dos trabalhos da escola, e o processo contribuiu para emergir novas percepções dessa relação: “A gente quer mostrar que apesar de nós sermos alunos de escolas públicas, o pessoal acha [...] que a gente não tem um senso crítico instigado [...], mas a gente, através da ocupação, quer mostrar que a gente tem vez, a gente tem voz." (Entrevista Rosa). Nos relatos dos/das secundaristas, é recorrente a 
abordagem de transformação, uma escola antes e outra escola depois das ocupações. Antes, um ambiente de descomprometimento; depois, um espaço no qual o estudante se sente pertencente.

Destarte, é explícito o desejo do/da estudante de ter uma escola mais democrática, com temáticas e abordagens mais próximas da realidade cotidiana. Eles demandam uma "educação como prática de liberdade" (FREIRE, 1981). Sobre essa lógica, em um dos relatos dos secundaristas emerge um questionamento sobre a escola estar transformando-se em um verdadeiro depósito de crianças e adolescentes, em vista da frágil participação das famílias e da comunidade no cotidiano escolar. Culturalmente, a escola é vista na sociedade como um espaço para "prender" os jovens, um lugar seguro onde eles permaneçam para que a família possa trabalhar tranquila.

É destaque também nas contranarrativas a relação construída entre escola e manifestações artísticas, o que nos remete a uma das áreas de intervenção da educomunicação: a expressão comunicativa através das artes (SOARES, 2011). Em uma imagem compartilhada na página Ocupa Augusto Ruschi, há escadas e paredes da sala de aula pintadas a partir da temática do rap, junto com a frase "Se a minha escola fosse assim, eu não faltaria nunca." (OCUPA AUGUSTO RUSCHI, 2016, doc. não paginado) . Nessa mesma página, outras postagens corroboram com essa perspectiva - uma delas é uma nota convidando a comunidade para grafitar o muro da frente da escola, utilizando a hashtag “\#bora_deixar_a_escola_mais_bonita”.

É perspicaz salientar essa apropriação de diferentes linguagens - como o grafite, a ilustração e também a música - que aparece nas contranarrativas como forma de traduzir o que se sente e que se quer para a escola e a educação. Tal linguagem lúdica também é acionada para pautar, no espaço da escola, questões relacionadas às minorias sociais (como denota a Figura 3, sobre discriminação racial). 
"De tanto poupar em educação, ficaremos ricos em ignorância": contranarrativas juvenis no movimento de ocupação de escolas no

Figura 3 - Print Screen de publicação que ilustra a discriminação contra pessoas negras
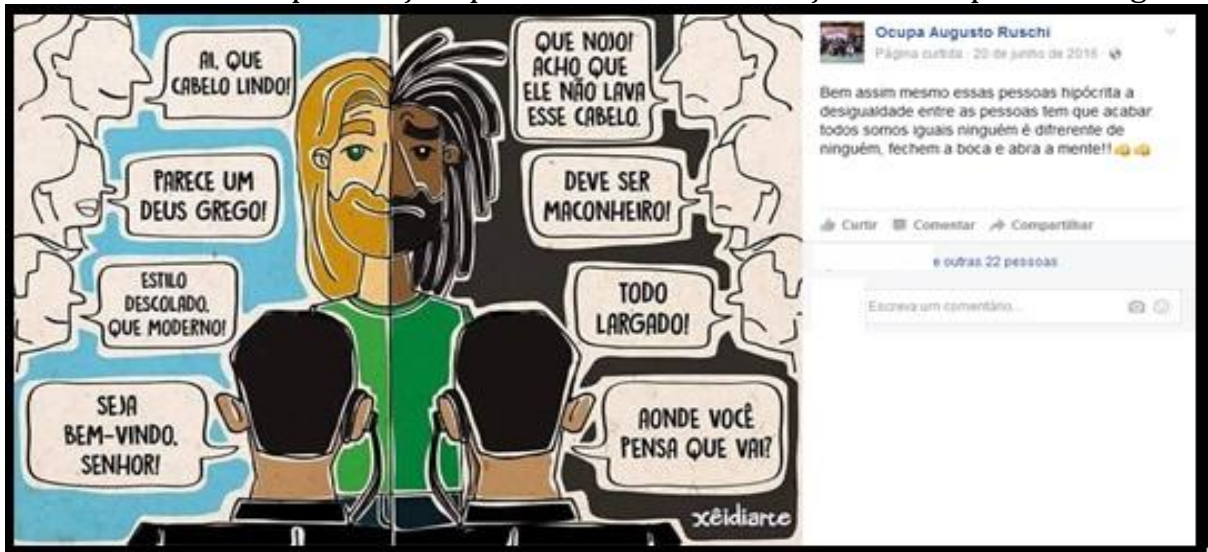

Fonte: Ocupa Augusto Ruschi (2016).

Além disso, nas contranarrativas das Fanpages observamos a preocupação com o uso da letra " $\mathrm{x}$ " como marcador neutro de gênero, usado para referir-se tanto a ela quanto a ele, como no caso de uma frase publicada na página Ocupa Cilon Rosa: “\#OcupaCilon. Estamos ocupadxs lutando pela educação! Isso aqui vai virar o Chile! Mulher bonita é a que luta. Quem luta, aprende e educa." (OCUPA CILON ROSA, 2016). Outro fato que remete a essa percepção é que, durante o movimento estudantil, algumas escolas ocupadas tinham um único banheiro, sem distinção de gênero.

Outra percepção é a recorrência, nas contranarrativas das redes sociais, da figura do atual governador do estado, José Ivo Sartori, como uma forma de denotar a indignação dos/das secundaristas com o descaso do poder público com a educação. Um exemplo está no conteúdo de um vídeo compartilhado tanto no canal do YouTube da ocupação da escola Augusto Ruschi quanto na sua página.

0 vídeo é uma edição simples de uma entrevista do governador que viralizou nas redes, na qual ele fala sobre o piso salarial dos professores da educação básica, nos seguintes termos: "Eu fui lá no CPERS [Centro dos Professores do Estado do Rio Grande do Sul - Sindicato dos Trabalhadores em Educação] e não assinei o documento, exigindo um compromisso de, de pagar ou resgatar o... o... o salário....... vamos dizer... o... como é que se diz... o piso... Sim, o piso eu vou lá na Tumelero ${ }^{7}$ [...]" (SARTORI, 2016, doc. não paginado). 0 vídeo ironiza o depoimento, repetindo várias vezes e de forma satírica o trecho "[...] o piso eu vou lá na Tumelero [...]".

\footnotetext{
7 Trata-se da maior rede de lojas de materiais de construção do estado do Rio Grande do Sul.
} 
Além disso, outro detalhe do audiovisual é que a imagem do governador aparece em preto e branco; logo após, entra um fundo musical, e a fachada da escola aparece com o cartaz "Augusto Ruschi Ocupado, 2016, Zona Oeste" acompanhada de imagens do bairro e de crianças jogando bola - cenas já em cores. Compreendemos essa forma de produção e edição como um recado da importância e como uma justificativa da ocupação, representando o movimento estudantil como uma esperança, uma alternativa à indiferença do Estado. Remete também ao apoio dos/das estudantes aos professores e às professoras, que, por meio de greves, lutaram sozinhos contra a precarização da educação pública por um longo período.

A partir desse percurso descritivo-analítico sobre como os estudantes secundaristas mobilizaram-se e apropriaram-se das redes sociais para construir uma autocomunicação de resistência, identificamos elementos que nos permitem concluir também o caráter educomunicativo de tais práticas e contranarrativas construídas nesse contexto de participação em um movimento social. A seguir, apresentamos os resultados sistematizados:

\subsection{Produção comunicativa, estudante como interlocutor}

Inspirado na perspectiva de educação libertadora de Paulo Freire, Kaplún (2002) compreende que uma comunicação educativa caracteriza-se por um processo de participação, reflexão, ação e dialogicidade entre os sujeitos interlocutores. Aprender e comunicar fazem parte de um mesmo processo cognitivo. A apropriação assertiva do conhecimento será mais efetiva na medida em que o educando/a educanda tem a possibilidade de expressar/comunicar o que aprendeu, em um processo de ação-reflexãoação sobre a realidade: "Aprende-se de verdade o que se vive, o que se recria, o que se reinventa e não o que simplesmente se lê e se escuta. Só há um verdadeiro aprendizado quando há processo; quando há autogestão dos educandos." (KAPLÚN, 2002, p. 47, tradução nossa).

Com base nessa perspectiva, observamos os processos comunicativos desenvolvidos no contexto do movimento de ocupação de escolas como educativos, uma vez que foram construídos a partir de uma comunicação horizontal na qual os estudantes foram os produtores de discursos, representações e sentidos midiatizados nas redes sociais. Peruzzo (2000, p. 218) salienta a importância da participação no processo de intervenção: 
A participação na comunicação é um mecanismo facilitador da ampliação da cidadania, uma vez que possibilita a pessoa tornar-se sujeito de atividades de ação comunitária e dos meios de comunicação ali forjados, o que resulta num processo educativo, sem se estar nos bancos escolares.

Tal constatação está explícita tanto na forma de organização dos/das estudantes caracterizada pela liderança coletiva, organização de atividades por setores, debates, reuniões, assembleias, gestão democrática - quanto pela rica produção comunicativa que emergiu desses espaços. Desde o uso de diferentes linguagens (vídeos, textos, fotografias, músicas, fanzines, desenho, grafite, eventos) a estratégias criativas (uso de figuras de linguagem, rimas) adotadas pelos próprios estudantes. Mesmo que constatemos erros de ortografia, por exemplo, nos materiais produzidos, é preciso reconhecer a importância da interlocução no processo de autocomunicação e de autorrepresentação vivenciado e construído pelos jovens. Nessas práticas de gestão participativa das páginas nas redes sociais, produção de conteúdo, edição de materiais e cobertura de eventos, identificamos áreas de intervenção da educomunicação (SOARES, 2011), como a gestão compartilhada da comunicação, a expressão comunicativa através das artes e o uso e apropriação da mediação tecnológica de forma educativa.

Essas áreas remetem a diferentes ações e princípios da educomunicação, que promovem a democratização da comunicação como direito humano, a dialogicidade nos espaços formais e informais de aprendizagem, o desenvolvimento de sujeitos individuais e coletivos, explorando a potencialidade das múltiplas linguagens em um contexto educativo plural, lúdico e voltado ao exercício da cidadania. Nesse cenário, os estudantes não são produtores e receptores, mas sim interlocutores.

\subsection{Comunicação/educação horizontal, democrática e participativa}

Este ponto está diretamente entrelaçado com o anterior, mas é destacado para enfatizar que a ideia, a qual emergiu nos espaços sociais das ocupações, foi a da comunicação e da educação dialógica. Um exemplo é o relacionamento, na comunidade educativa, entre docentes e discentes. A partir de uma aproximação maior (que envolvia inclusive passar a noite compartilhando o mesmo espaço), houve um movimento de construção de outros vínculos, somado à desconstrução de hierarquias. Professores e 
professoras relataram que tiveram oportunidade de dialogar com os estudantes, contar e escutar histórias de vida, o que contribuiu para uma maior aproximação com os/as jovens.

Podemos inferir que, nesse cenário, promoveu-se a ideia de uma educação dialógica, na qual "[...] conhecimento não se estende do que julga sabedor até aqueles que se julga não saberem; o conhecimento se constitui nas relações homem-mundo, relações de transformação, e se aperfeiçoa na problematização crítica dessas relações." (Freire, 1977, p. 22). Essa aproximação solidária entre professores e estudantes em um ambiente informal de aprendizagem foi importante para ambos, mas uma professora da escola Cilon Rosa destaca que, para os professores, foi "uma oportunidade de aprenderem a valorizar as diferenças entre os estudantes, descontruir padrões, uma vez que a categoria dos professores de educação básica é ainda muito conservadora." (Entrevista Rosa II).

Além disso, outro ponto a ser destacado é a politização e a motivação pós-ocupações dos estudantes em criar ou retomar grêmios estudantis, de forma a continuarem participando das decisões na própria escola, exercitando práticas democráticas. Tal ato nos remete ao exercício da cidadania comunicativa, entendido por Mata (2006, p. 10, tradução nossa) "[...]como o reconhecimento da capacidade de ser um sujeito de direito e de demanda no campo da comunicação pública, e o exercício desse direito."

\subsection{Leitura crítica da cobertura feita pela mídia hegemônica}

0 caráter educativo desse contexto de mobilização dos/das estudantes também se configura pelo fato desses jovens se aproximarem e compreenderem a lógica de produção e veiculação da comunicação hegemônica, desenvolvendo, a partir dessa experiência, a consciência crítica em relação às coberturas realizadas. Esse cenário remete-nos à área de intervenção social Educação para a Comunicação, destaque nas práticas e princípios da educomunicação, que vê na formação de um sujeito crítico, tanto em relação à mídia quanto aos demais fatores que o cercam, um processo fundamental para a constituição do cidadão politizado e atuante na sociedade.

Ao acompanhar as notícias veiculadas sobre o movimento estudantil, perceber contradições entre o que era dito nas entrevistas e o que era traduzido e publicado, identificar os enquadramentos adotados pelos veículos -interesses por trás desse cenário midiático -, os sujeitos apreendem que "O mundo é editado, ou seja, ele é redesenhado num trajeto que passa por centenas, às vezes milhares, de mediações, até que se manifeste no 
rádio, na televisão, no jornal, na cibercultura. Ou na fala do vizinho e nas conversas dos alunos." (BACCEGA, p. 25, 2009). Não obstante, a experiência tornou-se ainda mais rica pelo aprendizado de reedição desse mesmo mundo por meio das contranarrativas dos/das estudantes, que tensionaram a representação midiática por meio da publicação de notas de repúdio à imprensa, dissecando de forma crítica e argumentativa as notícias publicadas sobre as ocupações e suas incoerências no prisma dos secundaristas. Desta forma, o potencial educativo, nesse contexto de produção comunicativa no âmbito de um movimento social, dá-se também, como aborda Peruzzo (2007), pela produção de conteúdos que levam à compreensão dos mecanismos da estrutura de poder e das relações sociais e à desmistificação da mídia.

Nesse ponto, consideramos importante destacar que, independente do tipo de avaliação realizada em relação à mídia hegemônica, o fundamental em tal contexto é a imersão do sujeito num processo maior de formação crítica. Ou seja, o despertar de uma identidade politizada e com capacidade de discernimento, que vai emergir também em outras circunstâncias e espaços de sociabilidade - isso em relação aos próprios pais e mães, ao governo, na rua e também na sala de aula. Um dos professores da escola Maria Rocha, por exemplo, destacou que "A comunidade docente vai ter que saber lidar, se preparar para encontrar, no retorno das aulas, estudantes mais críticos." (Entrevista Rocha). Esse alerta vai ao encontro da perspectiva de educação comunicativa e libertadora de Freire (1981), capaz de formar sujeitos autônomos inseridos no e com o mundo.

\subsection{Constituição de ecossistemas comunicativos}

Se, na natureza, as interconexões entre os seres vivos são vitais para manter o equilíbrio do ecossistema ecológico, na escola (e nos diferentes espaços sociais) também é medular a interação dialógica entre os diferentes sujeitos que integram a comunidade educativa - família, professores e professoras, estudantes, colaboradores e colaboradoras, comunidade do bairro, etc -, fenômeno que, no âmbito de estudos e práticas da educomunicação, compreendemos como ecossistemas comunicativos. Soares (2011, p. 44) define tal conceito como "[...] um ideal de relações, construído coletivamente em dado espaço, em decorrência de uma decisão estratégica de favorecer o diálogo social, levando em conta, inclusive, as potencialidades dos meios de comunicação e de suas tecnologias". 
Nesse sentido, o desenvolvimento de ecossistemas comunicativos constitui uma estratégia para a criação de um espaço educacional democrático e participativo. Partindo desse conceito, acreditamos que, no contexto das ocupações, os jovens secundaristas criaram um rico e eficiente ecossistema comunicativo. Tal constatação pode ser ilustrada a partir de diferentes práticas: as oficinas, rodas de conversas e eventos em geral, realizados nas ocupações, abriram as portas da escola a profissionais de diferentes áreas - da música, da culinária, de movimentos sociais, da universidade -, promovendo a interação entre a comunidade escolar e a comunidade externa através da arte, do conhecimento e da solidariedade. Outro fato é o envolvimento da comunidade (os pais, por exemplo) nas atividades cotidianas das ocupações, como a preparação das refeições e as doações de alimentos, produtos de limpeza, gás de cozinha, cobertores, entre outros.

Essas práticas foram mediadas pela apropriação das redes sociais, como o Facebook, canal que potencializou (através da troca de mensagens e das publicações) a comunicação do movimento com outras escolas ocupadas, com pais e mães, com apoiadores e apoiadoras. Essa conjuntura causou também um estranhamento/desconstrução interessante na comunidade escolar, como destaca a professora da escola Cilon Rosa, para quem, culturalmente, a escola é vista como "Um espaço deliberado apenas para estudantes, docentes e colaboradores." (Entrevista Rosa II). Logo, nesse cenário, é explícito o desenho de uma escola como um espaço público aberto a todos/todas, justamente o contrário da perspectiva de "escola como depósito", criticada pelos estudantes. Esse espaço, aberto à participação social para formação de ecossistemas comunicativos em prol da educação, remete-nos ao sábio provérbio africano: "É preciso uma aldeia inteira para educar uma criança".

\subsection{Interdisciplinariedade/aprendizados plurais}

O dia a dia das ocupações nas escolas foi marcado por uma agenda intensa de atividades. Oficinas, eventos, reuniões com autoridades, reuniões com outros estudantes e docentes, passeatas e participação em assembleias. "Hoje a aula é na rua", diziam os cartazes expostos pelo movimento. As discussões promovidas nesses contextos, principalmente quando nos referimos às rodas de conversas (assim mencionadas pelos/pelas estudantes), foram marcadas pela interdisciplinariedade e por temáticas transversais que inquietam o cotidiano juvenil. 
Temas como direitos das crianças e dos adolescentes, opressão social, gênero e diversidade sexual, literatura, discriminação racial, análise crítica de músicas, gastronomia, representações midiáticas, filosofia, política, legislação, políticas públicas, sustentabilidade, esportes, etc. Tais abordagens plurais mencionadas denotam o caráter formativo da experiência, ilustrando a perspectiva de Gohn (2011, p. 333), que afirma que os movimentos sociais "[...] são fontes de inovação e matrizes geradoras de saberes", espaços de educação política. Como afirma a professora da Escola Estadual Professora Margarida Lopes, "Nenhuma aula, por melhor que fosse na sala de aula, ia ser tão rica quanto essa vivência que eles tiveram na ocupação." (Entrevista Lopes).

Além disso, o professor da Escola Estadual de Ensino Médio Professora Maria Rocha destaca que um dos principais legados das ocupações é o aprendizado sobre a responsabilidade de todos em relação aos espaços públicos, que pode ser exemplificada pelo ato de consertar/pintar/limpar espaços da escola: "Eu tenho certeza que se algum aluno que não participou da ocupação estar pichando uma porta de banheiro, não sou eu que vou ter que falar. Os alunos que viveram na escola nesse período é que vão monitorar e espalhar essa consciência." (Entrevista Rocha). Tal perspectiva dialoga com a abordagem de Castells (2013) sobre o conceito de um movimento social. Segundo ele, independente do sucesso das reivindicações e das pautas, todo o processo e experiências vividas pelos participantes é o maior legado de uma luta coletiva, na medida em que essas se perpetuam na formação dos sujeitos, nos seus modos de ser e estar no mundo - terreno rico para a mudança cultural, social e política.

\subsection{Educação intercultural e formação cidadã}

Pieroni, Fermino e Caliman (2014) discutem a importância de pensarmos a educação em uma perspectiva intercultural. Para eles, é emergente a necessidade de construirmos uma escola não mais voltada apenas a saberes utilitários, mas voltada à alteridade, na qual o mais importante seja aprender a estar junto no diálogo, no acolhimento, em um intercâmbio constante, respeitando e reconhecendo a riqueza recíproca dessa convivência, valorizando as diferenças que nos constituem como sociedade intercultural.

No contexto das ocupações escolares, observamos a preocupação dos/das estudantes com essa formação, colocando-a em pauta e em prática, através da criação de um banheiro único, por exemplo, em várias escolas. Além disso, os alunos realizaram oficinas e 
rodas de conversas sobre questões relacionadas a gênero, a orientação sexual, discriminação social, violência, desigualdade social, cultura, meritocracia, direitos humanos, entre outras temáticas que, em geral, não são contempladas pelos currículos escolares. Podemos inferir que os/as secundaristas colocaram em prática a perspectiva da educação intercultural, realçando o lugar da escola e dos processos educativos para "[...] a mudança intercultural e de construção dessa cultura do respeito, da abertura e do diálogo diante da diversidade cultural." (PIERONI; FERMINO; CALIMAN, 2014, p. 30).

\subsection{O/A jovem como ator social, produtor(a) de subjetividades rebeldes}

Destacamos, juntamente com o caráter educativo, a natureza emancipatória da participação do/da jovem secundarista no movimento de ocupação das escolas, devido ao afloramento de "subjetividades rebeldes e não conformistas", como aborda Santos (2007) e do jovem como sujeito na perspectiva de Touraine (1997, p. 85), na qual "o Sujeito é o desejo do indivíduo de ser um ator", de intervir na sociedade, ser protagonista da própria história. Com a experiência da luta estudantil, o jovem sentiu-se responsável por uma causa coletiva, percebendo a importância da mobilização, da rebeldia, do conflito e da resistência na conquista e manutenção de seus direitos, compreendendo o conceito de cidadania na prática. Isso também repercutiu na visão dos/das docentes em relação aos jovens: "A maior lição das ocupações é que a gente tem que olhar diferente para o nosso adolescente." (Entrevista Neves). É interessante constatar que essa consciência de mudança do olhar sobre o outro (adolescente) deu-se numa relação dialógica, despida da hierarquia professorestudante.

\section{Considerações finais}

Num prisma geral, podemos inferir que o movimento estudantil secundarista no Rio Grande do Sul constituiu um importante espaço de exercício democrático, de resistência e protagonismo juvenil mediado pela comunicação. Constatamos a existência de uma gestão participativa, capaz de mobilização, negociação e resiliência, articulação interna e externa, além de consistência crítica e política nas contranarrativas dos/das estudantes nas escolas e nas redes online. 
As práticas comunicativas foram marcadas por um processo horizontal e participativo explícito na realização de assembleias, reuniões, na tomada de decisões, na organização global da mobilização. Nas contranarrativas do Facebook, principal mídia apropriada pelos estudantes, é destaque o uso de diferentes linguagens, como fotografias, vídeos, notas conteúdos construídos com um perfil jovem, através do uso de hashtags, emoticons, de uma linguagem coloquial, própria da comunicação online. Tais contranarrativas desenvolvem uma autorrepresentação dos/das estudantes sempre em atividade, participando de oficinas, elaborando cartazes, construindo fanzines, limpando e organizando a escola. Esses espaços comunicativos também são usados para evidenciar as pautas do movimento e dar respostas à sociedade, esclarecer polêmicas, fazer denúncias, elaborar notas de repúdio à mídia, conjuntura que denota a configuração da identidade política e da resistência desses jovens ativistas da educação pública.

Dessa forma, concluímos que o movimento de ocupação de escolas por estudantes secundaristas no Brasil e, em específico, no Rio Grande do Sul (nosso foco) constituiu uma importante ação coletiva na luta pela educação básica e pública, historicamente precarizada. Além de conquistas pontuais intrincadas às reivindicações dos estudantes, destacamos o rico processo da educação para a cidadania que emergiu nessa conjuntura, processo que suscita muitas reflexões no âmbito da educação, da comunicação e suas interfaces.

\section{Financiamento}

Coordenação de Aperfeiçoamento de Pessoal de Nível Superior (Capes).

\section{Agradecimentos}

Agradecemos aos secundaristas e professores, sujeitos que participaram da pesquisa nos revelando a realidade.

\section{Referências}

ABRAO, Alexandre; DUARTE, Carlos; CARVALHO, Liliane; PERES, Renato. Não é sério. In. JÚNIOR, Charlie Brown. Nadando com os tubarões. Virgin, 2000.

ACABOU A PAZ, isto aqui vai virar o Chile! Direção, Produção e Roteiro: Carlos Pronzato. Edição: Lucas Duarte de Souza. São Paulo, 2016.60min. Disponível em: <https://www.youtube.com/watch?v=LK9Ri2prfNw>. Acesso em: 7 set. 2018. 
"De tanto poupar em educação, ficaremos ricos em ignorância": contranarrativas juvenis no movimento de ocupação de escolas no

BACCEGA, Maria Aparecida. Comunicação/educação e a construção de uma nova variável histórica. Comunicação e educação: revista do departamento de comunicações e artes da ECA/USP, São Paulo, v. 14, n. 3, p. 19-28, 2009.

CASTELLS, Manuel. Redes de indignação e esperança: movimentos sociais na era da internet. Rio de Janeiro: Zahar, 2013.

FREIRE, Paulo. A educação como prática da liberdade. Rio de Janeiro: Paz e Terra, 1981.

FREIRE, Paulo. Extensão ou comunicação? Rio de Janeiro: Paz e Terra, 1977.

GIL, Antônio. Métodos e técnicas de pesquisa social. São Paulo: Atlas, 2008.

GOHN, Maria da Glória. Movimentos sociais na contemporaneidade. Revista Brasileira de Educação, Rio de Janeiro, v. 16 n. 47, p. 333-361, maio/ago. 2011.

JOHNSON, Telma. Pesquisa social mediada por computador: questões, metodologias e técnicas qualitativas. Rio de Janeiro: E-papers, 2010.

KAPLÚN, Mário. Una pedagogia de la comunicación. La Habana: Editorial Caminos, 2002.

MALDONADO, Efendy. Transmetodología, cidadania comunicativa e transformação tecnocultural. Intexto, Porto Alegre, n. 34, p. 713-727, set./dez. 2015. Edição especial.

MATA, María Cristina. Comunicación y ciudadanía: problemas teóricos-políticos de su articulación. Fronteiras: Estudos Midiáticos, São Leopoldo, v. 8, n. 1, p. 5-15, jan./abr. 2006.

OCUPA AUGUSTO RUSCHI. 2016. Disponível em:

<https://www.facebook.com/OcupaAugustoRuschi/>. Acesso em: 5 set. 2018. Material de pesquisa.

OCUPA CILON ROSA. 2016. Disponível em: <https://www.facebook.com/ocupacilonrosa/>. Acesso em: 10 set. 2018. Material de pesquisa.

PERUZZO, Cicília. Comunicação comunitária e Educação para a cidadania. Revista Comunicação e Sociedade, Braga, v. 14, n. 1-2, p. 651-668, 2000.

PERUZZO, Cicília. Direito à participação comunitária, participação popular e cidadania.

Revista Lumina, Juiz de Fora, v. 1, n. 1, jul. 2007.

PIERONI, Vittorio; FERMINO, Antonia; CALIMAN, Geraldo. Pedagogia da alteridade: para viajar a Cosmópolis. Brasília: Líber Livro, 2014.

RIO GRANDE DO SUL. Assembleia Legislativa. Projeto de Lei 44. Dispõe sobre a qualificação de entidades como organizações sociais. 2016. Disponível em:

$<$ http://www.al.rs.gov.br/legislativo/ExibeProposicao/tabid/325/SiglaTipo/PL/NroPropos icao/44/AnoProposicao/2016/Origem/Px/Default.aspx>. Acesso em: 7 set. 2018.

RIO GRANDE DO SUL. Assembleia Legislativa. Projeto de Lei 190. 2015. Institui, no âmbito do sistema estadual de ensino, o "Programa Escola sem Partido". Disponível em: 
"De tanto poupar em educação, ficaremos ricos em ignorância": contranarrativas juvenis no movimento de ocupação de escolas no

$<$ http://www.al.rs.gov.br/legislativo/ExibeProposicao.aspx?SiglaTipo=PL\&NroProposicao= 190\&AnoProposicao=2015\&Origem $=\mathrm{Dx}>$. Acesso em: 7 set. 2018.

SANTOS, Boaventura de Sousa. Renovar a teoria crítica e reinventar a emancipação social. São Paulo: Boitempo, 2007.

SARTORI, José Ivo. 2016. Depoimento transcrito do vídeo “Ocupa Augusto Ruschi”. Disponível em: <https://www.youtube.com/watch?v=fudwWy3Er00 $>$. Acesso em 27 set. 2018.

SOARES, Ismar de Oliveira. Educomunicação: o conceito, o profissional, a aplicação: contribuições para a reforma do ensino médio. São Paulo: Paulinas, 2011.

SOARES, Ismar de Oliveira. 2012. Depoimento transcrito do vídeo "Educomunicación 2.0". Disponível em: <https://www.youtube.com/watch?v=JD8Di8qyv6g>. Acesso em: 20 ago. 2018.

TOURAINE, Alain. Iguais e diferentes: poderemos viver juntos? Lisboa: Instituto Piaget, 1997.

\title{
"From so much to save in education we will be rich in ignorance": juvenile counter narratives in the movement of occupation of schools in Rio Grande do Sul
}

\begin{abstract}
The movement of occupation of Brazilian public schools by secondary students in the period of 2015-2016 was a phenomenon that showed the youthful role and marked the precariousness of basic education in the discussions of the public and media agenda. In addition to the occupation of the schools and the streets, the students used social networks like Facebook to express their opinions and demands. Starting from this scenario, our main objective is to investigate how the secondary students of Rio Grande do Sul mobilized and used online social networks to build a communication of resistance and self-representation. To do so, we will use a combination of methodological approaches such as exploratory research, semistructured interviews and online-systematic observation of the Facebook pages of the schools occupied by the students. As a result, we can highlight the existence of a participatory and collaborative management, mobilization capacity, critical and political posture in relation to the hegemonic media, propositive in relation to public education, and the use of creative strategies and languages in self-communication and self-representation. This scenario refers to the communicative education character
\end{abstract}


"De tanto poupar em educação, ficaremos ricos em ignorância": contranarrativas juvenis no movimento de ocupação de escolas no Rio Grande do Sul

of the practices built in the student mobilization in favor of public education

\section{Keywords}

Public education. Secondary student movement. Communicative education. Online social networks. Counter narratives.

Recebido em 18/12/2017

Aceito em 21/03/2018 